\title{
HEBERDEN SOCIETY
}

\section{Heberden Round}

Prof. J. Goslings conducted the annual Heberden Round at the University Hospital, Leyden, on April 25,1958 . His theme was the association of pericarditis and rheumatoid arthritis. Thirteen patients were presented, three of whom had come to autopsy. Most of the patients had severe active rheumatoid arthritis, and some had other visceral involvement. Several showed the lupus erythematosus cell phenomenon. In four patients, however, pericarditis had been recognized where the duration of rheumatoid disease was less than 18 months. The clinical recognition of pericarditis was sometimes difficult, as physical signs might be transient and the electrocardiogram negative in cases showing pericarditis at autopsy. Prof. Goslings thought that the difficulty of detecting pericarditis during life might explain some of the difference between the reported prevalence of pericarditis in patients with rheumatoid arthritis and that seen in autopsy series.

\section{Joint Meeting of the Heberden Society and the Dutch Society of Rheumatologists}

At a meeting held on April 26, 1958, the following papers were given:

J. A. Szirmai (Leyden): Quantitative Aspects of the Metachromatic Reaction.-The interaction between cationic dyes and anionic polysaccharides was characterized by two interdependent reactions: metachromasia and the formation of relatively insoluble precipitates. The stoichiometry of the second type of reaction was described and it was shown that both the carboxyl and sulphate ester sites participated in this reaction.

The quantitative aspects of the interaction between cationic dyes and tissue components had been studied, using rooster comb and cartilage. The amount of the dye bound in the polyacid-dye complex could be determined quantitatively from the optical density of a dye solution after immersion of a piece of tissue in it. Various factors influencing this reaction, such as the tissuedye ratio, the dyebath concentration, the thickness of the tissue section, and mechanical agitation, had been studied. Under standard conditions the amount of dye bound by a given tissue depended only on the $\mathrm{pH}$ of the dyebath. It was suggested that electrostatic interaction between the cationic dye and the anionic sites of the tissue was primarily responsible for the dyebinding, and that the value obtained was a measure of the free anionic sites in a tissue.

The quantitative nature of this reaction had been further studied by comparing the mucopolysaccharide content of the tissues with their dyebinding properties.
This had been done on the fresh tissue before and after water extraction and on the water extract. The molar ratio of dye bound to anionic sites of the polysaccharides varied between $1 \cdot 1: 1$ and $1 \cdot 8: 1$, with the exception of the rooster comb extract where it was $1: 1$. This indicated that, except in the latter case, in addition to the acid groups of polysaccharides other anionic sites were also responsible for dye uptake.

The results showed that, in spite of the stoichiometric character of the interaction between cationic dyes and acid mucopolysaccharides, this method could not be used for the quantitative determination of mucopolysaccharides in tissues, as it measured the total number of free anionic sites and thus gave only a rough approximation of the amount of acid mucopolysaccharides present. In many cases such an approximate measure could be useful; this was shown by the close correlation between the metachromatic staining and the dye uptake of the tissues studied. The quantitative nature of this reaction suggested its usefulness for direct microspectrophotometric measurements of the metachromasia in tissue sections.

L. T. F. L. Stubbe (Leyden): Occult Faecal Loss of Blood Caused by the Use of Acetylsalicylic Acid.Occult loss of blood in the faeces was proved to occur in about 70 per cent. of the 180 persons to whom acetylsalicylic acid in the form of tablets had been administered with milk or water shortly after a meal. A meat-free diet was prescribed and the patient was not allowed to brush his teeth. As a rule the meat-free diet was prescribed after the patient had been taking acetylsalicylic acid for 14 days.

The first three lots of faeces after the diet had been started were not used. Only positive or negative reactions found in three successive lots of faeces were recorded. The concentration of the benzidine solution used was about 0.75 per cent. For quantitation, five different grades were established (from negative to strongly positive) according to the speed at which the colour of the reaction developed. When no acetylsalicylic acid was taken, the benzidine reaction was always negative. It was possible to demonstrate spectroscopically and spectrophotometrically that a positive benzidine reaction after the taking of acetylsalicylic acid was due to the presence of blood.

Results obtained in the 140 patients admitted to the wards of the Rheumatology Department who were treated with acetylsalicylic acid were entirely comparable with those found in the control group consisting of forty healthy volunteers.

It was possible to prove conclusively that the acetylsalicylic acid was the cause of this loss of blood as this phenomenon appeared to be reproducible. The quantity of acetylsalicylic acid administered did not have a 
conspicuous influence on the occurrence or severity of the blood loss. The most common doses were 1,500 and $3,000 \mathrm{mg}$. per day.

Identical results were obtained when acetylsalicylic acid in powder form suspended in water was administered to a small group as when the same persons were given this drug as tablets. Of the ten patients who were examined after they had taken coated tablets of acetylsalicylic acid, only two showed a negative benzidine reaction. After administration of sodium salicylate tablets the benzidine reaction was always negative.

In a number of persons it was shown, on the basis of the strength of the benzidine reaction, that the quantity of blood lost when acetylsalicylic acid was taken might not always be negligible. It was found that when $4 \mathrm{ml}$. blood was administered orally during a day (ten times $0.4 \mathrm{ml}$.) there was a strongly positive benzidine reaction. This suggests that a patient with a strongly positive reaction may lose about $30 \times 4 \mathrm{ml}=120 \mathrm{ml}$. blood per month, which may be comparable with the average menstrual loss, stated to be $40 \mathrm{ml}$.

E. KRUYFF (Wassenaar): Incidence of Leukaemia in Patients with Ankylosing Spondylitis treated with $\boldsymbol{x}$ Rays.-In a group of 1,996 Dutch patients with ankylosing spondylitis treated with radiotherapy, in whom a follow-up rate of over 90 per cent. had been achieved, there had been 256 deaths, 25 of which were due to leukaemia or aplastic anaemia, thus confirming the enhanced incidence of leukaemia after radiotherapy (Van Swaay, 1950). These figures were compared with those obtained for England and Wales by the Medical Research Council, but the statistics were not strictly comparable because of differences in dosage, age, and completeness of follow-up (46 per cent. in the M.R.C. series). Several instances of leukaemia in patients treated with deep $x$ rays for conditions other than ankylosing spondylitis were reported. The incidence of leukaemia was steadily rising in the Dutch population as a whole.

S. A. DEN OUdSTEN AND B. SPEyer (Rotterdam): Spontaneous Fractures in Rheumatoid Arthritis.-During the last 10 years 1,104 patients with "definite" rheumatoid arthritis (American Rheumatism Association criteria) were seen in South Rotterdam, which has a population of 235,000; 206 of these could be placed in Stages III and IV of the A.R.A. classification. Population studies indicated that 90 per cent. of all cases of rheumatoid arthritis were registered by the arthritis service. Of these 206 severer cases, 157 were available for a study of the prevalence of spontaneous fractures.

Nine patients showed non-spinal spontaneous fractures, seven of them in the femoral neck. The patients ranged in age from 25-85 years, 105 being over 60 . In a control group of 105 non-rheumatoid patients over 60 years of age and comparable to the older rheumatoid patients as regards sex, age, and physical incapacity, spontaneous fractures were found six times. The difference between these groups was not significant. The incidence of non-spinal spontaneous fractures was significantly greater in invalids than in non-invalids and they occurred more frequently in women than in men.

Spinal fractures were found in four patients in the 3 rheumatoid group and in four out of a second control $\square$ group of 157 patients without rheumatoid arthritis. In? women spinal osteoporosis was found significantly more often in the rheumatoid group than in the control group, but the possibility that this difference was due to the degree of incapacity could not be excluded.

Spontaneous fractures were seen in two out of fourteen $\overline{\bar{c}}$ patients who had been on long-term corticosteroid市 therapy, and in eleven of 143 patients who had never received these hormones. The difference was notes statistically significant.

H. A. Valkenburg AND C. A. DE Mos (Leyden): Latex-Fixation Test as a Diagnostic Aid.-The latex- T) fixation test (Singer and Plotz, 1956) was reviewed and $\overline{.}$ slight modifications introduced. Instead of borate $-\vec{V}$ buffer, glycine-buffer (pH 8.2) was used, and after incubation in a waterbath at $56^{\circ} \mathrm{C}$. the tubes werew allowed to stay at room temperature for 20 to $24 \mathrm{hrs}$. Incubation at $37^{\circ} \mathrm{C}$. was omitted, as false positiveo reactions resulted. Examined in this way, 110 of $120_{-}^{\circ}$ serum samples obtained from 54 patients were repro $r$ ducible within two dilutions. Statistical analysis of the serologic procedure showed the latex test to be a reliable routine test. When exceeding a titre of $1: 20$, patients 3 were considered to have a positive latex-fixation test. As many sera showed a marked prozone effect, a $1: 20^{-}$ dilution could not be used for a screening proceduge $\overrightarrow{0}$ A considerable proportion (about 10 per cent.) of sermis samples in the non-rheumatoid groups which exhibißi. this prozone phenomenon were called weakly positi Varying proportions of gamma globulin and/or latexparticles were shown to be only partly responsible for these weak reactions.

Serum samples from 1,023 patients and controb subjects were investigated, American Rheumatism Association criteria being used for the rheumatoic arthritis group of 337 patients. Of 238 patients with "definite" rheumatoid arthritis, 207 (87 per cent.) showed positive reactions. 53 patients suffering from "definite' rheumatoid arthritis complicated by a positive L.E.-cel巴 phenomenon exhibited positive reactions in 90.6 per cent Only four of sixteen patients with "definite" rheumatoiof arthritis complicated by psoriasis were positive. $30 \%$ (83.3 per cent.) of 360 patients with non-rheumatoid disease gave negative latex-fixation tests. This group included 23 patients suffering from systemic lupug erythematosus and five with scleroderma; positive reactions were seen in 35 and 80 per cent. respectivelyg Positive results were found in 11.8 per cent. of a group of 101 patients with non-rheumatic diseases and ins 7.6 per cent. of 225 normal subjects. When corrected for weak reactions, the percentages of positive reactions in the "definite" rheumatoid group and the normaw control group were 84 and $3 \cdot 1$ per cent. respectivelyo Taking all non-rheumatoid patients together, 3.6 ped cent. gave strong positive reactions. A follow-u战 investigation would be necessary to determine the possible significance of weak reactions. 
W. Humans AND H. R. E. Schuit (Leyden): Lupus Erythematosus Cell Phenomenon.-Lupus erythematosus cells could be found in diseases other than systemic lupus erythematosus, and therefore this phenomenon could not be regarded as absolutely specific. Of a series of 2,000 patients, two hundred were found to be positive, and only one of the positive cases could not be classified as belonging to the group of the so-called collagen diseases. This phenomenon might therefore be used as a tool for further investigation of this group of diseases.

A sound basis for further studies was provided by standardization of the technique, and quantitation of this phenomenon. Positive sera on dilution showed gradually decreasing ability to produce L.E. cells and these were never observed in dilutions greater than $1: 32$.

In recent years the hypothesis that the L.E. cell is the result of an immunological mechanism had received strong support. Additional data were presented, in accordance with this concept whereby nucleoprotein, or part thereof, but not desoxyribo nucleic acid, could be regarded as antigen and the L.E. cell factor as autoantibody. It proved possible to absorb L.E. sera with nuclei from different sources as thymocytes and chick erythrocytes in a quantitative way as well as with purified nucleoprotein preparations. The final proof of this concept was still lacking. Apart from a more detailed chemical definition of the active component of the nucleoprotein, it had still to be shown that this component could act as an antigen.

Although it was tempting to ascribe a role in the pathogenesis of some of the collagen diseases to the L.E. cell factor, there was no direct proof of this assumption. There were indications that the presence of this factor should be regarded as an epiphenomenon.

A. VAN DEN Hooff, W. Hijmans, and M. J. W. KASTELEIN (Leyden): Ultrastructure of Streptococcal L-Forms.-L-forms of Group A beta-haemolytic streptococci were studied under the electron microscope. By making use of the property of these fragile organisms to grow into the agar medium, it was possible to make ultrathin sections of total $\mathrm{OsO}_{4}$-fixed cultures in agar, embedded in methacrylate.

The cultures were found to consist of thin-walled vesicles up to several micra in diameter, each with a distinct outer limiting membrane and a rather irregular wall-structure. Moderately osmophilic granules varying from 300 to $3,000 \AA$ were found embedded in the vesicle walls. In addition "microvesicles" of 100-300 $\AA$ were observed in the vesicle walls; all these wall structures were bulging into the interior of the vesicles; only the largest granules $(3,000 \AA)$ were bulging outward or lying free.

Each vesicle contained an irregular system of thin membranes attached to the vesicle wall or floating free. Attached to these membranes were granules, a few hundred $\AA$ in size, showing marked osmophilia. Transitions between the largest granules and the vesicles were observed.

On the basis of the observations described, a tentative hypothesis concerning the developmental cycle of the
L-forms was put forward. The basic transformation was thought to consist of a vacuolization and swelling of compact full-size granules into vesicles; at the same time, by a budding mechanism, small granules developed in contact with the inside of the vesicular wall. When full-grown, these granules became detached and vacuolized, thus starting a new cycle. Whether the microvesicles played a role in morphogenesis could not be decided. The nature of the intravesicular system of membranes and granules was obscure.

The question was raised whether the structures found were components of the normal bacteria, rendered visible by a partial disintegration effect.

J. M. F. LANDSmeER (Leyden): Functional Anatomy of Finger Movements.-Contraction of the long tendons of a finger tended to produce a zig-zag deformity of the proximal and middle phalanges. The direction of movement of these phalanges depended on the forces acting on the individual bones, and these forces were related to the distance of the line of pull of the tendons from the centres of rotation of the interphalangeal joints over which they passed. In the normal finger, this zig-zag change was prevented by a system of muscular and ligamentous checks at the metacarpal and interphalangeal joints, but disease of these joints such as occurred in rheumatoid arthritis would displace the line of pull of the tendons, or the site of action of the checking mechanisms, and might accentuate rather than prevent the natural tendency to "zig-zag".

A most enjoyable social programme included a reception by the Burgomaster of Leyden in the historic Lakenhal, a visit to the Bulb Research Institute, and a dinner held under the auspices of the International Study Centre for Rheumatic Diseases, Amsterdam. Dr. J. Van Breemen, Honorary President, and Professor P. Formijne, President of the International Study Centre, Dr. J. J. de Blécourt, on behalf of the Dutch Society of Rheumatologists, and Prof. Goslings welcomed the members of the Heberden Society.

Dr. Van Breemen gave the following dinner toast:

Mr. Chairman, my fair ladies, and gentlemen, I am most happy to see so many English colleagues in the campaign against rheumatism in my own country.

The first group of English doctors as students of the rheumatic diseases came to Amsterdam in 1929, when the Dutch Society against Rheumatic Diseases was founded, but I had then already had for many years very valuable connexions with my English colleagues through my friend Dr. Fortescue Fox, president of the International Society of Medical Hydrology. I can tell you without flattery that this co-operation opened quite a new world for me. I owe my education as a rheumatologist partly to France and England, for in my own country it was practically taboo to say anything about rheumatic diseases in distinguished medical circles. Next to Dr. Fortescue Fox I see the ghosts of many English colleagues. 
In 1928 , this young man, my neighbour, Dr. Will Copeman, came as secretary to the annual general meeting of the I.S.M.H. at Amsterdam, and a congress was held under my presidency. Among the members of that I.S.M.H. congress were many members of the present Heberden Society, and in that year was founded the Ligue Internationale Contre le Rhumatisme.

But the real contact with your society took place when in an unguarded moment $I$ became honorary member of the famous Royal Society of Medicine, and I was asked to come to London to accept my degree. Without a banquet this could of course not take place! and before the banquet $I$ had a very interesting correspondence with the director, Mr. Edwards, who insisted on calling me "professor"; I had to answer him that I did not hold this title in Holland, but he remained very obstinate. The President at that dinner was a Heberden man and he wittily said: Dr. van Breemen of Amsterdam, you are a Dutchman, and that is in England something very special, for we English people are used to say the following: "God damned the world, but Holland dammed itself".

This was much to the point, and I must confess that my
English colleagues are right: we Dutchmen cannot stop making dams and not only in the material sense but also spiritually; every dike is a pillar and not always a pillar on of wisdom.

Now please allow me to give this folder with souvenirs about England to you for your historical museum at Portland Place in London, and I propose that we drink $\frac{\bar{O}}{5}$ all together from this "loving cup", a present given to $\overline{\bar{c}}$ me in 1938 on the tenth anniversary of the foundation $\vec{\nabla}$ of the Ligue Internationale Contre le Rhumatisme, and $\unrhd$ offered by Mrs. Copeman on behalf of the English \& members. I hope that Professor Formyne will allow us $\overrightarrow{0}$ to drink every ten years from this cup!

Replying on behalf of the Heberden Society, the ${ }^{\omega}$ President, Prof. J. H. Kellgren, thanked the speakers for their welcome and hospitality, congratulated? them on the excellence of the scientific programme they had arranged, and expressed the hope that this $\omega$ meeting would set a precedent for further equally $\mathscr{W}^{-}$ successful joint meetings in Great Britain and the $\mathrm{o}$ Netherlands.

\section{A.D.A.R. \\ Asociación de Ayunda al Reumático}

A new association for the support of research, treatment, and education in the field of rheumatic disease was founded in Buenos Aires on June 18, 1958.
Full information regarding the aims and constitks tion of the association may be had from the Presidene

Elena Luro de Arana, Juncal 783, Buenos Aire్ Argentina.

\section{“A I R" \\ ARCHIVES OF INTERAMERICAN RHEUMATOLOGY}

This is a new journal published in Brazil and edited by Drs. Bonomo and Mizraji, with the help of a strong editorial board representative of all parts of the Americas. It enjoys the blessing of the Pan-American League, whose President contributes a foreword. All the contents are in three languages -English, Spanish, and Portuguese. A criticism of the standard of translation into English in some places is perhaps justified.

This issue contains eight articles on subjects which range from the electrophoretic study of serum proteins in rheumatic fever, to the treatment of rheumatoid arthritis with Benemid. These are mostly well written and interesting (although it is $\overrightarrow{\vec{O}}$ unfortunate that parts of two of them have been 3 printed upside down!). There are also valuable abstracts of the contents of the other rheumatism? journals of the world, a "Question and Answer" " section of lesser value, and an interesting "Miscellaneous" section, which concludes this rather bulky but well-produced volume. The last contains inter alia an account of the IX International Congress of $\mathrm{O}$ Rheumatology held in Toronto in June, 1957, and the report of the Committee on Nomenclature of the 을 International League against Rheumatism. W.S.C.C.

\section{NEW YORK RHEUMATISM ASSOCIATION}

$$
\text { Officers, 1958-59 }
$$

At the Annual Meeting of the New York Rheumatism Association held on April 8, 1958, at Cornell University, the following officers were elected:
President: Dr. Edward W. Lowman

Vice-President: Dr. Emanuel Rudd

Secretary-Treasurer: Dr. Albert W. Grokoest, 622 $\stackrel{\mathcal{D}}{?}$ West 168th Street, New York 32, N.Y. 